\title{
EDUCAÇÃO ONLINE: POR METODOLOGIAS INOVADORAS PARA O FÓRUM
}

CONGONHAS/MG JUNHO/2018

\author{
Carmem Lúcia da Silva - VIR ZOOM - cls.ead@gmail.com \\ Tipo: Investigação Científica (IC) \\ Natureza: Relatório Final de Pesquisa \\ Categoria: Métodos e Tecnologias \\ Setor Educacional: EDUCAÇÃO CONTINUADA EM GERAL
}

\begin{abstract}
RESUMO
A investigação buscou identificar os tipos de interação, reativas ou mútuas, que foram praticadas, na relação dos alunos com o professor e tutor nos fóruns de uma das disciplinas de um curso de pósgraduação online Lato sensu na área da saúde. A metodologia se deu em uma abordagem qualitativa com o uso da observação, análise documental e entrevista semi-estruturada. As interações na relação dos atores, se apresentaram do tipo reativa, suscitando por metodologias inovadoras para a dinâmica dos fóruns.
\end{abstract}

Palavras-chave: Educação online. Interação. Fórum. 


\section{INTRODUÇÃO}

A Educação a Distância em sua trajetória utilizou-se de diferentes aparatos tecnológicos para se realizar. Neste contexto, foram sendo modificadas as possibilidades de interação na relação dos atores. Na educação à distância por correspondência, rádio e televisão, possibilitavam-se apenas as interações reativas.[1] Ao fazer uso do telefone para as teleconferências e o microfone para as videoconferências, abriu-se possibilidade de interação mútua,[2] necessariamente sincrônica.

Com o advento do computador conectado à internet apresentam-se possibilidades de comunicação sincrônica e assincrônica através dos ambientes virtuais (AVA) nas interfaces fórum, chat, Wiki. Acontece a Educação online modalidade de Educação a Distância cujos suportes são os artefatos tecnológicos, computador ou celular, conectado à internet, possibilita-se multi-interações[3], construção e reconstrução de conhecimento através das interações na relação dos atores que poderão atuar como autores da produção do conhecimento em atividades de construção coletiva, considerando-se que as tecnologias digitais não somente se transformam com o tempo, mas também "transformam o seu tempo." (PRIMO, 2007, p. 1).

Paralelamente, vislumbra-se pelo paradigma emergente[4], que provoca a realização de práticas pedagógicas inovadoras, a superação da fragmentação do conhecimento, formando o ser humano integral evidenciando diálogo nas ações, trabalho coletivo e a efetiva participação de forma crítica de professores e alunos (BEHRENS, 2005).

$\mathrm{Na}$ educação online, cuja oferta de cursos cresce exponencialmente, os fóruns se apresentam como um espaço para a promoção do debate, a reflexão a efetiva construção do conhecimento. Contudo é preciso verificar como este espaço vem sendo utilizado, "sob pena da subutilização das potencialidades operativas e colaborativas das interfaces do computador e da web e do prejuízo à educação autêntica baseada metodologias dialógicas." (SILVA, pág. 36, 2010)

O estudo se pautou pela questão: Como se dá a organização dos fóruns em um curso de pós-graduação Lato sensu na modalidade online, e quais as implicações nas interações dos atores? Nesse sentido, o objetivo da investigação foi identificar nos fóruns do AVA de um curso online, a forma de organização dos fóruns e suas implicações na interação dos atores. Os objetivos específicos foram: identificar as formas de organização dos fóruns e as interações praticadas, previstas ou espontâneas; Identificar e registrar o entendimento dos atores sobre os fóruns e as interações realizadas nesta interface. 


\section{METODOLOGIA}

A investigação se deu em um curso de pós-graduação Lato sensu com tema na área da saúde em uma instituição[5] que atua com formação de profissionais há mais de cinco décadas.

Optou-se pela abordagem qualitativa que tem no ambiente dos acontecimentos sua "fonte direta de dados e o pesquisador como seu principal instrumento." (LUDKE; ANDRÉ, 1986, p. 11). Optou-se pelo Estudo de Caso por privilegiar "uma observação detalhada de um contexto, ou indivíduo, de uma única fonte de documentos ou de um acontecimento específico." (BOGDAN; BIKLEN, 1994, p. 89). Para a coleta de dados utilizou-se da análise documental[6] que possibilita localizar fatos através de diferentes documentos (LÜDKE; ANDRÉ, 1986); , da observação, técnica que possibilita o contato pessoal e minucioso entre pesquisador e o objeto pesquisado e entrevistas semiestruturadas, pois estas a partir de

[...] certos questionamentos básicos, apoiados em teorias e hipóteses, que interessam à pesquisa, e que, em seguida, oferecem amplo campo de interrogativas, fruto de novas hipóteses que vão surgindo à medida que se recebem as respostas do informante. (TRIVINHOS, 1987, p. 146).

Dessa forma, é possível a compreensão dos acontecimentos a partir do partir do olhar do entrevistado.

\section{Corpus da pesquisa}

De acordo com a proposta pedagógica, o curso teve como referência um curso que a instituição já oferecia, na modalidade presencial. Com ele disponível na modalidade online, vislumbrou-se atender ao aumento da demanda de formação continuada na área.

O desenvolvimento do curso com carga horária total de quatrocentos e trinta e oito horas, contemplou cinco disciplinas no AVA, três encontros presenciais no prédio da instituição, e uma visita técnica. É foco da investigação em tela a primeira disciplina do curso (D1). Sua carga-horária foi de 70 horas, realizadas em um período de dez semanas e expectativa de sete horas de estudos semanais.

Foram analisadas as formas de organização da atividade fórum e os processos interativos na relação de um professor $\mathrm{P} 1$ e cinco alunos $\mathrm{A} 1, \mathrm{~A} 2, \mathrm{~A} 3, \mathrm{~A} 4$ e $\mathrm{A} 5$ e os processos interativos do T1 com estes cinco alunos.

Para análise dos tipos de interação na relação dos atores utilizou-se os conceitos de 
interação reativa que pressupõe a previsibilidade e o pelo estímulo-resposta (PRIMO, 2001) e interação mútua que tem como características, a cooperação, o intercâmbio, o debate, a transformação mútua e a negociação (PRIMO, 2001) e acontece necessariamente na relação das pessoas, diferente da interação reativa que pode acontecer na relação das pessoas e das pessoas com as máquinas. $\mathrm{Na}$ interação mútua, a perspectiva é da construção, reconstrução e produção do conhecimento de forma interdependente e recursiva. Divergir significa cooperar, não se trata necessariamente de consenso, de concordar. (PRIMO, 2007).

\section{ANÁLISE E DISCUSSÃO}

De acordo com as informações coletadas nos registros, memória[7] do Ambiente Virtual (AVA[8]), na (D1) foram abertos, na mesma data, três fóruns, ainda que com datas de encerramento descoincidentes, objetivos distintos e, demandando tarefas diferentes aos alunos.

De acordo com as informações coletadas no primeiro momento do curso no fórum 001 foram solicitadas aos alunos tarefas distintas: publicar naquele espaço informações pessoais; escolher um colega aleatoriamente, enviar mensagem para ele e interagir com a turma, expor seus sentimentos e percepções nesse primeiro contato com a comunidade de aprendizagem[9], responder a uma indagação acerca do que o aluno ouve falar do estudo do tema da pós-graduação, responder a uma questão sobre a expectativa do curso na sua vida profissional e pessoal. No final das orientações havia uma informação de que a participação no fórum valia dois pontos. Não foram informados, os critérios para avaliar a participação. Este fórum ficaria aberto por três dias.

A solicitação de mais de uma atividade no fórum 001 impossibilitou o efetivo debate na relação dos atores. A atividade no fórum precisa ser necessariamente o diálogo, mesmo sendo necessária a priori a leitura de texto para fundamentação suscitar a participação, apresentar questões problema e fomentá-lo no processo de mediação pedagógica. Fórum é um termo proveniente do latim do latim e tem no seu bojo o debate. Sendo ainda relacionado a "congresso, conferência que se envolve em debate de um tema" (HOUAISS, 2001, p. 1379). Este espaço precisa ser utilizado com tema que proporcionam o debate, construção e a produção de conhecimento.

Outro ponto é o fórum 001 apesar de cinco atividades ficaria aberto por apenas três dias, tempo este que foi prolongado, pois a maioria dos alunos não conseguiu cumprir as atividades no tempo estabelecido. Vavassori e Raabe (2003) deixam clara a 
possibilidade de promoção de debates em fóruns, em tempos prolongados. O tempo de duração dos fóruns é um aspecto importante a ser considerado, pois a lógica assincrônica dos fóruns é diferente da lógica sincrônica dos encontros da educação presencial, com todos juntos no mesmo local e horário.

No fórum 002 foi solicitado aos alunos, disponibilizarem uma entrevista que eles realizariam com um profissional da área estudada no curso e uma análise dela. Foram orientados ainda, a ler a entrevista de no mínimo dois colegas e comentar. Foi informado que a entrevista, análise e os comentários valiam cinco pontos. A previsão de tempo de duração deste fórum foi de quatorze dias[10]. Da mesma forma no Fórum 003 os alunos foram solicitados a publicar uma contribuição importante sobre os temas estudados e justificar a escolha. Estes dois fóruns 002 e 003 a data de início de sua realização foi concomitante ao fórum 001.

Um mês e dois dias depois do início dos três primeiros fóruns do curso e, dois dias antes, da previsão de término do fórum 003, foi aberto o fórum 004 com as seguintes orientações: organização pelos alunos, em grupo, de um quadro acerca das "Múltiplas e divergentes teorias". O trabalho seria postado por um representante do grupo e seria premiado o melhor trabalho. Na mesma orientação, informou-se que o fórum ficaria desativado, pois os quadros seriam postados em outro local a ser informado posteriormente, após verificarem o local adequado. Não foi indicado qualquer espaço no ambiente virtual para que eles pudessem formar o grupo, também não ficou disponível o chat[11]para que os alunos pudessem conversar entre si. Neste caso, o fórum foi utilizado para dar uma orientação para a atividade apenas. Seria o quadro de giz da educação presencial.

As orientações para os fóruns deixam claro que na D1, o fórum foi utilizado principalmente para produtos de atividades dos alunos, ainda que em alguns momentos a eles se solicitassem alguns comentários. Essa forma de uso nos parece inédita, inclusive porque não encontramos, na bibliografia consultada, qualquer menção a um fórum com tais características. O fórum foi utilizado, como se fosse um portfólio ao propiciar a visibilidade dos trabalhos dos alunos. Contudo, o portfólio não deve ser a compilação de toda a produção do aluno, mas, a seleção e apresentação dos melhores (VILLAS BOAS, 2007). Além disso, o portfólio deve possibilitar comentários construtivos (SANTOS, 2003). O que, contudo não se evidenciou no caso. Os comentários realizados pelos alunos de modo geral eram mensagens superficiais e "amigáveis" concordando ou informando que gostou, achou interessante. O portfólio, assim como o fórum, não deveria ser espaço para comentários como um simples parabéns, ou um "gostei!". Sua proposta deveria estar na perspectiva do avanço na reflexão, através das interações, 
para promover, pelo diálogo, a aprendizagem. Primo (2007) alerta para o fato de que o conflito de ideias não é antagônico à cooperação. Ao debater, discordar, apresentar outros pontos de vista, estaremos necessariamente cooperando com o grupo.

\section{'Os tipos de interação nos fóruns}

Nos registros do fórum 002, P1 no dia do fechamento do fórum postou uma mensagem informando seu entusiasmo com o empenho dos alunos, ressaltando que as entrevistas e a reflexão que eles fizeram sobre os conceitos ficaram muito bons, não houve, por parte de A1, A2, A3, A4 e A5 qualquer retorno a este comentário. Nos fóruns 001003 e 004 não havia qualquer mensagem de P1[12]. Na orientação do fórum 004, T1 termina a orientação com um atenciosamente, e assina seu nome.

Em entrevista A1 informou que no tempo do curso, gastou muito com ligações para colega para saber o que ele entendeu, mas, por vezes o colega também não havia entendido o conteúdo ou a proposta do lhe foi solicitado. Ligou também na instituição responsável pelo curso para falar com $\mathrm{P} 1$, pois sentia que ele tinha o conhecimento necessário para as orientações em detrimento de T1. No final, de acordo com A1 ele diz que aprendeu mais com as leituras que fez de textos que pesquisou na internet.

Os fóruns acabaram por ser um local para todo tipo de pergunta. T1 chegou a postar em um dos fóruns da D1 que ali não era local para responder indagações dos alunos, seja de que tipo for. T1 relatou em entrevista a partir do evento em questão, criou-se o cibercafé[13], espaço para assuntos gerais.

Em entrevista, T1 relatou que disponibilizou muitas horas respondendo dúvidas técnicas de alunos, apesar de saber que essa era a função do monitor técnico, mas não quis sobrecarregá-lo e também pelo fato de os alunos terem apresentado mais duvidas na usabilidade do AVA do que propriamente de conteúdo.

Correa (2002) afirma que papel do tutor não deve ser de um mero tira-dúvidas. Ao agir desta forma ele se torna um recurso do aprendente, passivo no aguardo de questionamentos, não atua de forma reflexiva e, por conseguinte não intervém no processo de aprendizagem e não o mediador tão necessário em situações de aprendizagem. De acordo com Rezende e Santos (2002) o termo tutor não traz, na sua raiz, aspectos fundamentais ao mediador pedagógico, que claramente esta no cerne do professor. .

As interações na relação de T1-A1, T1-A2, T1-A3 se caracterizam reativas. No caso de 
T1-A4 e T1-A5, não há, nos registros, dos fóruns da D1 qualquer interação. O que significa que A5 não procurou por $\mathrm{T} 1$ em qualquer momento. $\mathrm{O}$ inverso também não ocorreu embora, em entrevista, T1 tenha relatado que "um dos papeis do tutor é você chamar o aluno pro ambiente eu peguei esse papel mesmo e utilizava muito ele." Conclui-se que as atividades que A5 e A4 postaram nos fóruns não foram comentadas por T1. Da mesma forma, A4 e A5 não procuraram por T1 para esclarecer dúvidas.

Em entrevista, A4 relatou que os retornos de T1 eram fracos no sentido acadêmico, com pouca consistência no que tange o conteúdo, contudo, disse ainda, que os retornos de T1 atendiam na questão do acolhimento do aluno, mas não necessariamente da aprendizagem. Dessa forma, as interações que vislumbram a aprendizagem ficam prejudicadas.

\section{CONSIDERAÇÕES FINAIS}

A análise do curso o relato das entrevistas revelaram uma prática que privilegiou o aprender sozinho, pois se o aluno não procurou o tutor ou professor para esclarecer dúvidas, ele também não foi procurado.

No tempo da educação por correspondência, onde se fez uso da carta e havia uma preocupação manter o diálogo com o aluno, pois as cartas eram escritas em tom informal e pessoal vislumbrando promover uma relação amigável, proximidade entre ambos. Nos dados analisados na D1 o tom foi formal, sem utilizar alguma forma na comunicação para promover a proximidade.

Necessário se faz a formação de gestores, coordenadores e professores para: planejar o curso de acordo com as especificidades e necessidades da educação online; conhecer e atuar em cursos online utilizando as possibilidades dos ambientes virtuais de aprendizagem e o uso correto das interfaces, aprender a promover o debate.

O que se espera é o professor mediador, mas a estrutura, a forma de organização do fórum é essencial para que o desencadeamento das interações mútuas se realize. É urgente o uso de metodologias inovadoras que privilegie interações mútuas, construção, reconstrução e produção de conhecimento e a participação dos alunos, para além das notas, na perspectiva da avaliação formativa.

Em cursos online, é preciso, deixar disponível para os alunos, no ambiente virtual, possibilidades de encontros sincrônicos na interface chat, para que possam promover encontros entre eles, ou encontrar casualmente em caso de coincidir o acesso ao 
ambiente virtual ou encontros deles com o professor.

\section{REFERÊNCIAS}

BEHRENS, Marilda Aparecida. O paradigma emergente e a prática pedagógica. Petrópolis: Vozes, 2005.

CAIXETA, Juliana Eugênia; RIBEIRO, Lucas Benevides Lima; LEITE, Mayara Cristina de Medeiros. Um estudo teórico sobre as comunidades de aprendizagem na educação a distância. In: 3ํㅗimpósio Educação e Comunicação. Infoinclusão: possibilidades de ensinar e aprender. . Anais. 2012. Artigos, p.370-384. ISSBN 2179-4901. Disponível em: Acesso em: 03 maio 2018.

CORRÊA, Juliane. Reflexões sobre o desafio de ser tutor. Formação, Brasília, v.2, n.4, p. 35-42, jan.2002.

BOGDAN, Robert; BIKLEN, Sari Knopp. Investigação qualitativa em educação: uma introdução à teoria e aos métodos. Porto: Porto Editora, 1994.

HOUAISS, Antônio; VILLAR, Mauro; FRANCO, Francisco Manoel de Mello. Dicionário Houaiss da língua portuguesa. 3. ed. Rio de Janeiro: Objetiva, 2001.

LUDKE, Menga; ANDRÉ, Marli. E. D. A. Pesquisa em educação: abordagens qualitativas. São Paulo: EPU, 1986.

MORAES, Maria Cândida. Pensamento eco-ssistêmico: educação, aprendizagem e cidadania no século XXI. Petrópolis: Vozes, 2004.

PRIMO, Alex. Interação mediada por computador: comunicação cibercultura, cognição. Porto Alegre: Sulina, 2007.

PRIMO, Alex; TEIXEIRA, Fernando. Ferramentas de interação em ambientes educacionais mediados por computador. Educação, v. 24, n. 44, p. 127-149, 2001.

REZENDE, Flávia; SANTOS, Henriette dos. Formação, mediação e prática pedagógica do tutor-orientador em ambientes virtuais construtivistas de aprendizagem. Tecnologia Educacional, v. 31, p. 157-158, abr./set . 2002.

SANTOS, Edméa Oliveira dos. Articulação de saberes na EAD online: por uma rede 
interdisciplinar e interativa de conhecimentos em ambientes virtuais de aprendizagem. In: SILVA, Marco. (org.) Educação online. São Paulo: Loyola, 2003. p. 217-230

SILVA, MARCO. Educar na cibercultura: desafios à formação de professores para a docência em cursos online. Revista digital de Tecnologias Cognitivas, n. 3 janeirojunho 2010. Disponível em: Acesso em: 03 maio 2018

TRIVIÑOS, Augusto Nibaldo Silva. Introdução à pesquisa em ciências sociais: a pesquisa qualitativa em educação: o positivismo, a fenomenologia, o marxismo. São Paulo: Atlas, 1987. 175p.

VAVASSORI, Barreto Fabiane; RAABE, André Luís Alice. Organização de atividades de aprendizagem utilizando ambientes virtuais: um estudo de caso. In: SILVA, Marco. (Org.) Educação online. São Paulo: Loyola, 2003. p. 311-325.

VILLAS BOAS, Benigna Maria de Freitas. Portfólio, avaliação e trabalho pedagógico. Campinas: Papirus, 2007. (Coleção Magistério: Formação e Trabalho Pedagógico).

[1] Neste caso, relação do ser humano somente com a máquina (PRIMO, 2007).

[2] Acontece necessariamente na relação das pessoas.

[3] Interação reativa e mútua simultâneas. Conceito consta nas páginas 3 e 4 .

[4] Encontra-se "surgindo a partir de um novo paradigma científico", e é suscitado em "regime de urgência" (MORAES, 2004, p. 14).

[5] O nome da instituição é mantido em sigilo.

[6] Técnica cujo foco é obter informações dos fatos através de documentos (LÜDKE; ANDRÉ, 1986).

[7] Em virtude de a instituição ter trocado de AVA no decorrer do curso, quando do início da pesquisa este AVA não era mais utilizado para o curso. Coletaram-se informações dos registros dos fóruns.

[8] O nome do ambiente virtual será mantido em sigilo. 
[9] Compreende-se Comunidade de Aprendizagem "como um conjunto de pessoas que podem ou não ter interesses em comum, mas que geram espaços de zona de desenvolvimento proximal e, portanto, de negociação, que possibilitam posicionamentos diversos na atuação dentro e fora dos ambientes virtuais de aprendizagem." (CAIXETA; RIBEIRO; LEITE; 2012 p. 380) Levando-se em consideração a forma de organização dos fóruns notadamente na D1onde estabeleceu-se a interação reativa, na relação dos atores, a prática que se evidenciou não foi de comunidade de aprendizagem.

[10] Início concomitante ao fórum 001.

[11] Interface para encontros sincrônicos.

[12] P1 era também Gestor na instituição, por isso era possível ligar para ele.

[13] Este espaço também se revelou em completa desordem. Não foi objeto de nossa pesquisa para este trabalho por não se tratar de fórum entendido como atividade no curso. 